\title{
Study of Perceived Accessibility in Daily Travel within the Metropolis
}

\author{
Anastasia Vladimirovna Lukina ${ }^{1}$, Roman Roaldovich Sidorchuk ${ }^{1 *}$, Sergey Vladimirovich \\ Mkhitaryan ${ }^{1}$, Anastasia Alexeevna Stukalova ${ }^{1}$, Irina Ivanovna Skorobogatykh ${ }^{1}$ \\ ${ }^{1}$ Department of Marketing, Plekhanov Russian University of Economics, Moscow, Russian Federation
}

\begin{abstract}
The growth of metropolises and the number of vehicles cruising within their boundaries creates a permanent problem of dissatisfaction with transport accessibility. This study aims to identify the difference between perceived (PA) and objective (OA) transport accessibility. For its implementation, it was necessary: to explore PA between different residential areas and travel modes, reveal the influence of the travel regime on the PA, compare the impact of socialdemographic factors on the individuals' PA. The research methodology is based on a large crosssectional study with 2,275 respondents. A quota sample was used for 12 administrative districts of the Moscow metropolis. The data was processed by IBM SPSS Statistics 20 statistical program to obtain descriptive statistics indicators. Correlation analysis of the respondent's answers to the four items for PA assessment was performed to assess the relationship between the results of the solutions. Next, a synthetic index of PA was calculated and analyzed differences using the integral index PA. The relationship significance was assessed using F-criterion-based one-way ANOVA. The novelty of our study is as follows: it contributes to previous research on the possibility of measuring perceived affordability in metropolitan areas and benchmarking OA and RA.
\end{abstract}

\section{Keywords:}

Perceived Accessibility;

Urban Transport; Objective Accessibility;

Subjective Accessibility;

Travel Behavior; Urban Mobility;

Metropolis; Transport Research.

Article History:

Received: 17 September 2021

Revised: 12 November 2021

Accepted: 21 November 2021

Published: $01 \quad$ December 2021

\section{1- Introduction}

This article presents a study of the perceived transport accessibility in the metropolis of Moscow in daily trips. There are many different definitions for the concept of transport accessibility [1]. At the same time, various approaches to this concept consider urban traffic as the main factor affecting transport accessibility. In 2020, Moscow topped the Traffic Index rating of cities by traffic congestion compiled by the manufacturer of TomTom car GPS devices [2]. According to Ralf-Peter Schäfer, Vice President of TomTom for Traffic, "Against the background of global cities, the level of traffic flows in the Moscow agglomeration recovered quite quickly since Moscow, as an administrative, financial and transport center of the country, had to maintain its vitality and production activity, so even the introduction of remote work mode often covered only part of the employees in many organizations" [2].

At the beginning of 2021, the population of Moscow was 12655.1 thousand people. The population density is 4,940.5 people per sq. $\mathrm{km}$. The territorial division of Moscow consists of 12 administrative districts [3]. The red dots in Figure 1 show the districts of Moscow, and the colored lines show the structure of the main directions of public transport routes in Moscow, with over 14 million daily trips and over 5 billion trips per year. Currently, the city has a transport system, which includes the following modes of transport: Subway, including the Moscow Central Circle Road and the Moscow Monorail system (the share of the Moscow Metro in passenger transportation among other types of passenger transport in the capital is about 56\%, on average 9 million passengers use subway services on week days

* CONTACT: professor_sidorchuk@mail.ru

DOI: http://dx.doi.org/10.28991/esj-2021-01316

(C) 2021 by the authors. Licensee ESJ, Italy. This is an open access article under the terms and conditions of the Creative Commons Attribution (CC-BY) license (https://creativecommons.org/licenses/by/4.0/). 
according to the official website of the State Unitary Enterprise "Moscow Metro" [4]), urban and intercity rail transport (including urban streetcars), ground urban passenger transport (electric buses, cabs, shuttle buses, buses). Recently, the city authorities have paid special attention to developing individual mobility vehicles (bicycles, electric scooters, and others). Despite the saturation of the city with different types of transport, given the scale of the urban area and the uneven distribution of residence and workplaces (the city center has up to $40 \%$ of jobs, with less than $10 \%$ of the population), the perception of accessibility of work and other points of attraction (social facilities, shopping and entertainment enterprises) is becoming extremely relevant.

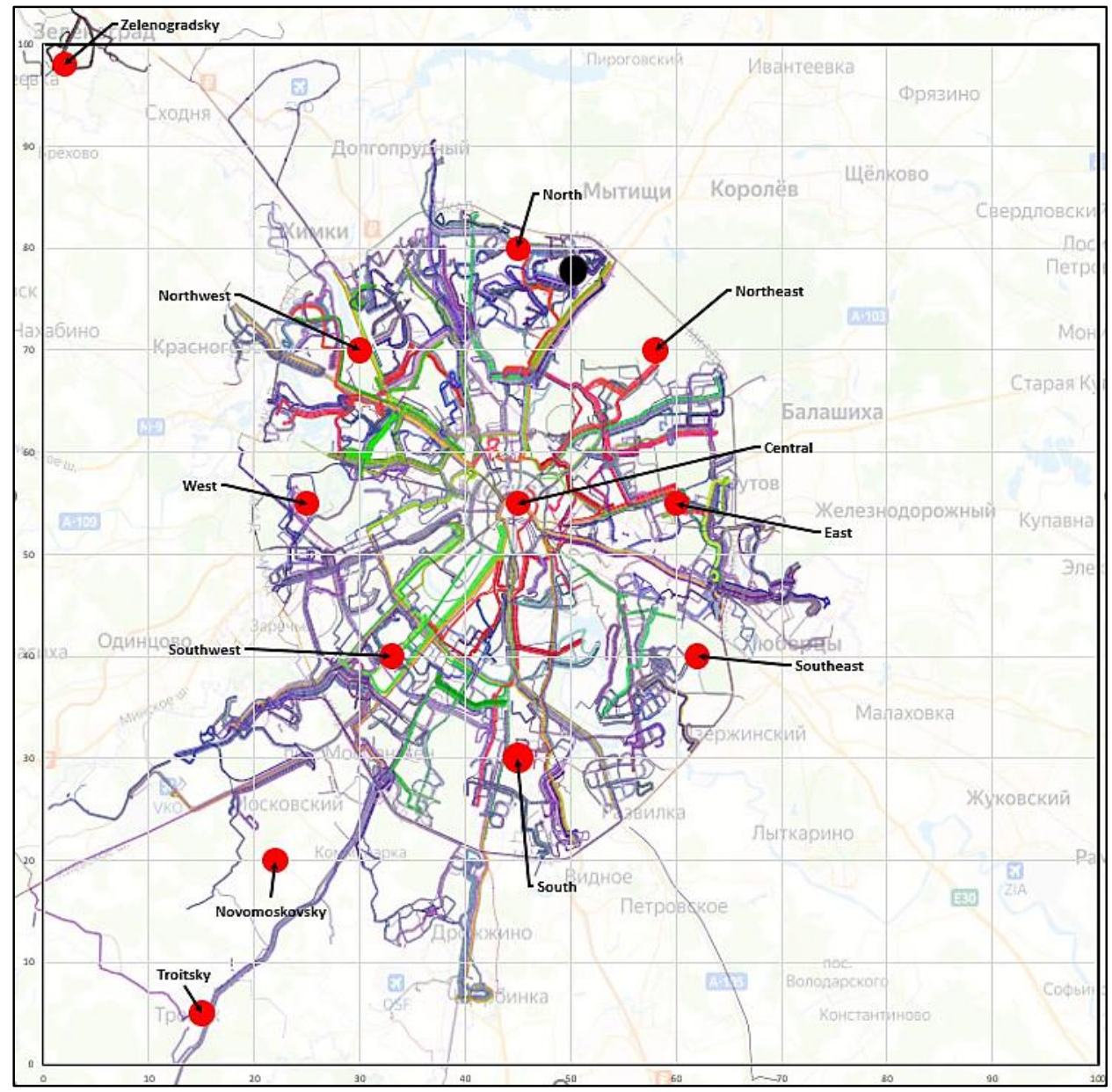

Figure 1. The structure of the transport system and the administrative districts of Moscow.

Until 2020, Moscow was also in the top ten in terms of traffic congestion which leads to problems for residents' daily trips, reduces their mobility options, and harms the city's environment. It not only decreases calculated accessibility but also reduces residents' transport accessibility perception, including a decrease in satisfaction with the use of public transport. Normative approaches to transport planning adopted in urban planning and management, based on rigid technological standards are insufficient in a modern metropolis [5]. Marketing has long used the perceived quality approach in satisfaction analysis based on customer experience [7]. The same approach can be used in transport accessibility [7]. Transport accessibility and mobility is a goal of transport policies throughout Europe [8], including Russia [9], including a separate program for the metropolis of Moscow [10]. At the same time, there is a common understanding of the limitations of objective (normative) indicators in assessing accessibility [1, 11]. Thus, there is a need to bridge the gap between the spatial dynamics of cities and the behavioral factors of individuals [12, 13]. That makes subjective approaches to accessibility assessment such as PA assessment an extremely relevant area for complementing current studies, implementing, and assessing the transport system accessibility in metropolises. The literature review conducted in our article revealed a certain lack of research in this area. To this end, we conduct a study of factors influencing the perception of PA and a comparative analysis of OA and PA. Thus, the goals of this study were as follows:

- Explore PA between different residential areas and travel modes;

- Compare the impact of social-demographic factors on the individuals' PA;

- Compare the OA and PA.

Based on the above objectives, the following hypotheses were developed: 


\section{1-1-Hypothesis 1 (H1)}

PA for residential areas of the city will be different.

\section{1-2-Hypothesis2 (H2)}

PA for the same residential areas is various when (if) residents prefer different travel modes for daily trips;

\section{1-3-Hypothesis3 (H3)}

Social-demographic factors define differences in perception of accessibility. The study was conducted in March 2020 before the introduction of restrictions on the movement of citizens and the self-isolation regime due to the COVID-19 pandemic using several methodological approaches:

- An online survey of urban residents was based on an online questionnaire of a quota sampling, proportional to the gender and age composition for each of Moscow's administrative districts. The survey was conducted based on the online panel [14], the quotation ensured the sample representativeness by gender and age, and 2275 people took part in the online survey.

- Statistical modeling methods were based on statistical data processing methods described in the literature $[15,16]$.

\section{2- Literature Review}

\section{2-1-Transport Accessibility Concept}

The term "accessibility for a metropolis" was introduced by Hansen [17], and it defines accessibility as the potential for the possibility of interaction. Hansen notes that "...that it is a measure of the intensity of the possibility of interaction rather than just a measure of the ease of interaction." [17]. In the same paper, he emphasizes that accessibility is constantly changing under the influence of different factors. Factor impact analysis of workplace, place of residence, points of interest, and cost were analyzed for London in the work of Dalvi and Martin [18] based on Hansen's model. At the same time, the authors did not include in their model the perception of accessibility. However, Hansen noted that accessibility is based on the ability and willingness of people or firms (behavioral aspect) to overcome spatial divisions. The spatial accessibility has been further supplemented in works [19-21]. An important area of research in the analysis of spatial accessibility has been the study of the accessibility of certain areas or objects: parks and other natural areas [22, 23] the accessibility of medical facilities [24].

An interesting study in the transport accessibility area became the review prepared for the New Zealand Transport Agency. This work analyzed the practice of measuring existing transport accessibility in some countries [25]. The paper identified accessibility indicators based on which accessibility is quantified and defined as the ease with which an individual can reach an object from their place of residence or another place using different travel modes. In addition, this work, as well as subsequent works, use for modeling such attributes as congestion, schedules, reliability of travel time [26-28]. In addition, the hours of operation of various services have a significant impact on modeling [29]. When modeling spatial interaction, these attributes are usually used without special consideration of PA [30]. As noted in some literature reviews on transport accessibility, it covers different areas of people's lives [31, 32]. In particular, an essential aspect of accessibility is an inclusive environment that allows for equal access to transportation facilities [33].

Another equally important issue is economic affordability. Although researchers often focus on minimizing passenger costs, this topic remains extremely important. For example, researchers analyze the impact of poverty on transport accessibility in Colombia, noting that the higher the household income, the higher their transport accessibility [34-36]. As other researchers have shown, even in wealthy countries, there is a problem of economic inequality in the provision of public transport and the risk of "transportation poverty" [29, 37, 38]. The local governments regulate public transport issues, including affordability [39, 40]. In turn, this kind of regulation cannot avoid the behavioral aspect of passengers (users of public transport services) [41, 42]. As studies show (for example, [12]), most authors believe that accessibility can be determined based on physical indicators, while the results show the need to study more subtle behavioral aspects.

A promising conclusion presented by Pot et al. [43] is that there is no such thing as objective accessibility in contrast to subjective accessibility. The authors justify their conclusion by saying that accessibility is not a function of land-use and transportation system configurations. Of course, it is possible to calculate accessibility using the data of land-use and transport system configurations, to set targets and make management decisions. However, these decisions will poorly reflect the real situation. That is because the actual potential for spatial interaction is conditioned by how the environment is perceived. Therefore, objective accessibility can be a proxy indicator for the experienced potential to interact with spatially dispersed activities [43]. Thus, it is correct to speak not about OA but calculated accessibility based on the land-use and transport data. So, precisely the PA assessment will make it possible to assess the reality of transport accessibility in a particular area. 


\section{2-2-Perceived Accessibility}

PA issue can be considered in terms of marketing provisions relying on irrational consumer behavior and considering accessibility as a set of services [14]. On the other hand, when examining the effectiveness of the normative approach to transport accessibility, it was noted that there is a gap between measured or calculated accessibility and the perception of accessibility by users. Perception is seen as something essential but difficult to quantify. At the same time, objective and subjective measures are more suitable to deepen understanding of accessibility [44]. Thus, the need to use both normative (objective) and subjective (perceived) indicators together is noted. Considering the concept of PA, we should agree with the authors who define it as "a combination of the opportunities provided at destinations and the resistance associated with reaching these locations" [43, 45]. Overcoming the quantitative accounting problem of perceived, subjective indicators is implemented in marketing [5, 14]. The analysis of the subjective factors of accessibility continued in subsequent studies based on comparing accessibility first using an objective approach and then a subjective one to compare results [46, 47]. Studies have noted the essential goal of accessibility - to improve the quality of life. In addition, the studies conclude that the weight and importance of objects for assessing accessibility (points of interest) should be determined by the attitude of residents (based on subjective assessment of accessibility) and then measured objectively.

Further research reflected the importance of understanding the PA phenomenon when proposed the Perceived Accessibility Scale in public transport [7]. A study by Lättman et al [13] examined the application of this scale in terms of inclusive accessibility. The paper defined perceived accessibility concerning how easy it is to lead fulfilling life using the transportation system, which does not necessarily coincide with objective indicators. In a follow-up study of the Perceived Accessibility Scale based on a survey of 1,237 public transport users, the results showed that this scale is a reliable measure [13].

The relationship between PA and satisfaction of different segments of the elderly was explored, expanding the social aspect of the study. The study showed a high degree of PA effect on overall life satisfaction [48]. Studies in Montreal have shown that a dissatisfaction index has been developed based on the Transport Accessibility Satisfaction Survey results. The authors suggested that working with this index would increase the PA of residents [49]. We should separately highlight studies of the PA effect on reducing road traffic and congestions. Here the critical problem is the transition from personal vehicles to public or sharing vehicles. Studies of satisfaction do not show a direct relationship with PA [50]. In this regard, the study of carsharing PA seems interesting. However, as the authors point out, the model developed explains only one-third of the differences in carsharing PA, which may serve as a defined limit to the applicability of the scale [51]. As studies in Madrid have shown, the solution to the transition of passengers to use public transport can be obtained by introducing restrictions or increased satisfaction with the use of public transport. At the same time, accessibility has not been noted by researchers as essential for users [52]. Thus, many authors conclude that PA depends on the physical environment and an individual's perception of the physical environment [43]. In this regard, we need to understand what factors will influence the perception of accessibility.

\section{3- Research Methodology}

\section{3-1-Sample Structure}

From March 03 to March 19, 2020, an online survey of Moscow residents (969 men (43\%), 1,306 (57\%) women, 2,275 in total) was conducted. The sample was quoted based on three parameters: gender, age of respondents, and administrative district of residence. The same number of respondents was interviewed in each administrative district of the city. Distribution within the quotas was performed based on statistical data on the distribution of the population by gender and age. The basis was the basis of the statistical digest data "Women and Men of Russia" [53] from the Federal State Statistics Service. Table 1 presents the distribution by age and gender for each quota of the administrative district.

Table 1. Segments of quotation in the online survey for each administrative district of Moscow.

\begin{tabular}{cccc}
\hline \multirow{2}{*}{ Age range } & \multicolumn{1}{c}{ Gender distribution (\% of the population) } & $\begin{array}{c}\text { Age range distribution } \\
\text { (\% of the population) }\end{array}$ \\
\cline { 2 - 3 } $18-29$ & Men, \% & Women, \% & 17 \\
$30-39$ & 11 & 9 & 22 \\
$40-49$ & 9 & 11 & 18 \\
$50-59$ & 7 & 9 & 19 \\
$60-65$ & 4 & 12 & 10 \\
$65+$ & 5 & 6 & 14 \\
Total & 44 & 9 & 100 \\
\hline
\end{tabular}


There are 12 administrative districts in the city of Moscow, so there are 144 quoted segments. A questionnaire converted into the form required for an online survey was developed as a research tool (https://ru.surveymonkey.com/r/NKYCWH2)

\section{3-2-PA Assessment}

To assess PA, we used the approach described by Lättman et al. [54]. Respondents indicated their level of agreement with four statements that "together were designed to measure overall PA of daily travel" [54]. We used a 4point Likert scale that included the following response options: "Strongly agree", "Somewhat agree," "Somewhat disagree", "Strongly disagree."

In addition, respondents were asked about their primary transport mode when moving around Moscow. This circumstance subsequently allowed us to analyze the differences in PA depending on the most frequently used travel mode in the city (test of $\mathrm{H} 2$ ).

The questions where respondents specified the district of residence allowed us to assess the differences in PA by districts of the city (test of H1).

Questions concerning gender, age, educational level, and employment status allowed us to examine PA in terms of socio-demographic characteristics of respondents (test of H3).

\section{3-3-Statistical Processing}

The data set was processed using the IBM SPSS Statistics 20 software package. Correlation analysis of the respondents' answers to the four items for PA assessment was performed to assess the relationship between the results of the answers. Next, a synthetic index of PA was calculated, defined as the average between the estimates obtained from the four statements on PA. Next, we analyzed differences using the integral index PA depending on a residential area, primary transport mode, gender, age-range, educational level, and employment status. The relationship significance was assessed using F-criterion-based one-way ANOVA. Schematically, the study methodology of PA is presented in Figure 2.

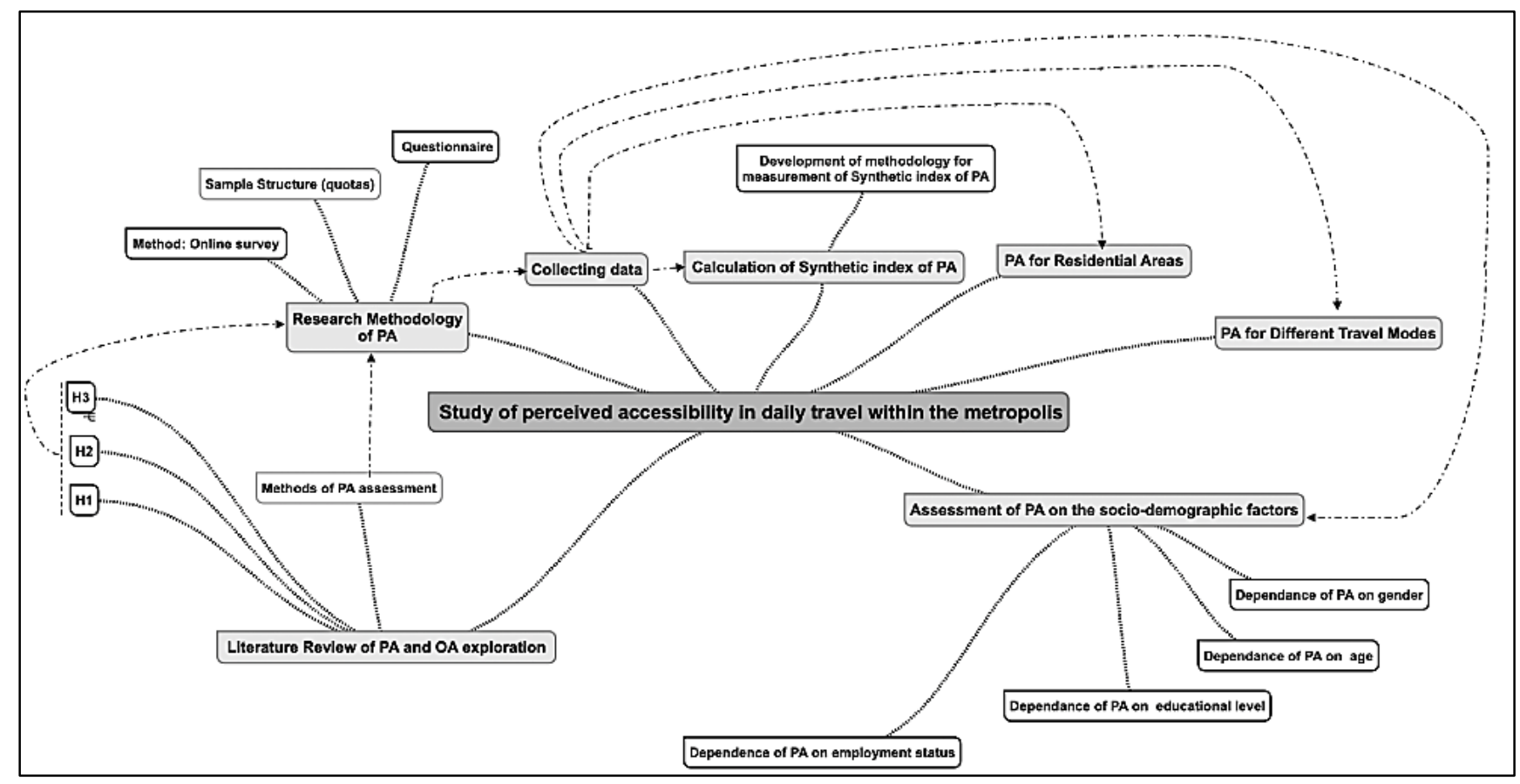

Figure 2. Research methodology flowchart.

\section{4- Results}

\section{4-1-Descriptive Statistics}

Our study showed that $85 \%$ of the respondents were between the ages of 18 and 59 . The distribution of respondents in the sample by age is detailed in Table 1. The employment status and educational level of respondents are shown in Figures 3 and 4. 




Figure 3. Employment status of respondents.

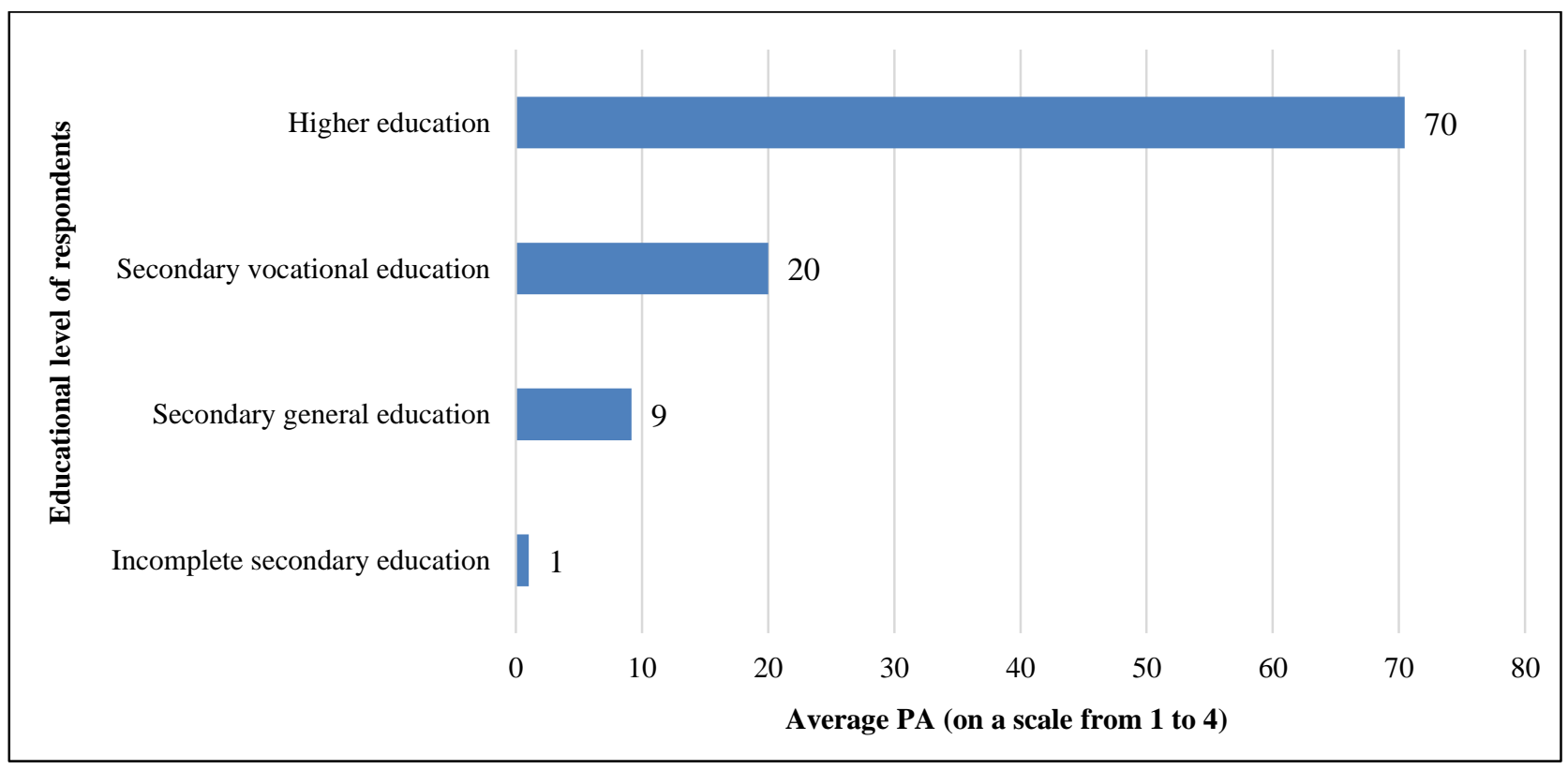

Figure 4. The educational level of respondents.

More than half of the respondents work full-time (51\%). The total share of employed is $63 \%$, and $23 \%$ of respondents are pensioners. We need the data on socio-demographic characteristics to test hypothesis 3.

The distribution of respondents' answers to the question about how they mostly move around Moscow is presented in Figure 5. The distribution of respondents' answers to the question about how they mostly move around Moscow is presented in Figure 5. We need the answers to this question in combination with the PA assessments to test hypothesis 2. It was multiple response questions with a list of possible answer options. The respondents could select a few options that are true for them. We need the answers to this question in combination with the PA assessments to test hypothesis 2 .

Public transport is a priority for half of the respondents (50\%) when moving around the city. 29\% of respondents indicated mostly walking. $27 \%$ use personal transport as the primary means of moving around the city. A much smaller number uses taxes $-12 \%$, carsharing $-3 \%$, micro mobile transport (bicycle, scooter, monowheel, segway) $-2 \%$. Notify that not adapted for micro-mobility, the transport system of Moscow only in the last few years is actively adapting for micro-mobility. Bicycle lanes are appearing, traffic rules for micro-mobility are being formed. That is partly why very few residents use micro-mobility as their primary travel mode to get around the city. In addition, the length of the trip from the city boundaries to the city center varies on average from $16 \mathrm{~km}$ to $31 \mathrm{~km}$, so the possibility 
of using micro-mobility as the primary urban travel mode is limited due to long distances. Table 2 presents the correlation analysis of respondents' answers to the four statements determining PA. Since they answered the question on a 4-point Likert scale, and the distances between the closest answer options are assumed to be approximately the same, further analysis could be conducted both in ordinal variables and in quantitative ones.

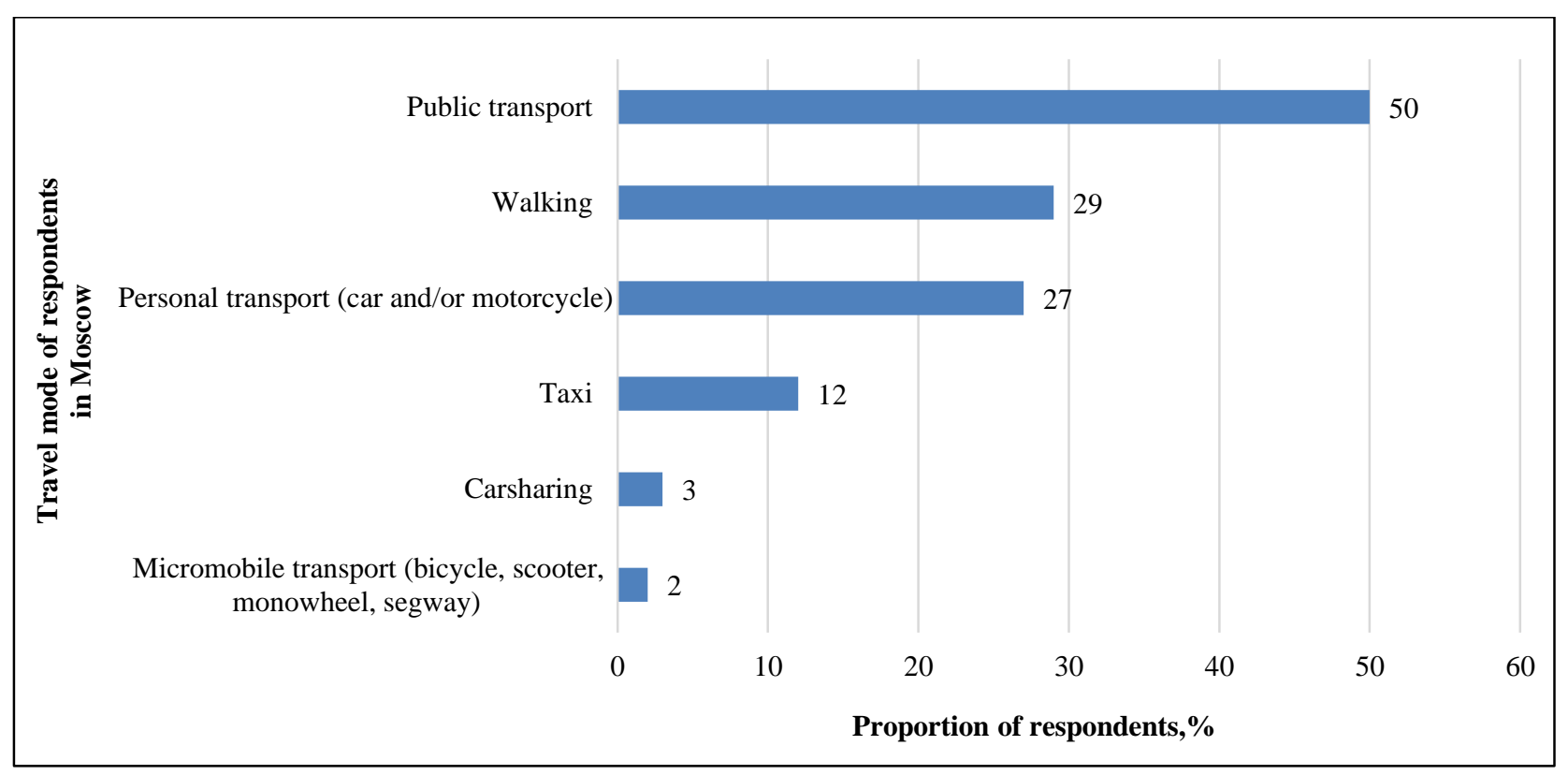

Figure 5. Priority transport modes to move around the city.

Table 2. Pearson's matrix of pair correlation coefficients.

\begin{tabular}{lccc}
\hline & $\begin{array}{c}\text { Given the way I move around } \\
\text { town today, my daily } \\
\text { activities are easy to do }\end{array}$ & $\begin{array}{c}\text { Given the way I move } \\
\text { around town today, I } \\
\text { can live the life I want }\end{array}$ & $\begin{array}{c}\text { Given the way I move } \\
\text { around town today, I } \\
\text { can do whatever I need }\end{array}$ \\
\hline $\begin{array}{l}\text { Given the way I move around } \\
\text { favorite activities is satisfactory } \\
\text { town today, my daily activities } \\
\text { are easy to do }\end{array}$ & 1.00 & 0.67 & 0.67 \\
\hline $\begin{array}{l}\text { Given the way I move around } \\
\text { town today, I can live the life I } \\
\text { want }\end{array}$ & 0.67 & 1.00 & 0.74 \\
\hline $\begin{array}{l}\text { Given the way I move around } \\
\text { town today, I can do whatever I } \\
\text { need }\end{array}$ & 0.67 & 0.74 & 1.00 \\
\hline $\begin{array}{l}\text { Given the way I move around } \\
\text { town today, access to my } \\
\text { favorite activities is satisfactory }\end{array}$ & 0.58 & 0.66 \\
\hline
\end{tabular}

Correlation analysis showed a moderate (correlation coefficient exceeding 0.5) and strong (exceeding 0.7) relationship between the variables (Table 1), which indicates the similarity of each respondent's answers to the compiled questions. The results obtained allow us to calculate the integral index of PA and further analyze the change of the index under the effect of different factors to test the hypothesis.

\section{4-2-Statistical Analysis and Assessment of Integral Index of PA}

This section presents the results of PA assessment based on the integral index of PA and PA integral index assessment in different city districts, depending on the primary way of moving around the city and on the sociodemographic characteristics of the respondents.

\section{4-3-Integral Index of PA}

Due to a high degree of correlation in the responses to the four statements regarding PA (see Table 2), a synthetic, integral index of PA was formed, which sufficiently reflects the effect of each of the four indicators. The average value of the four variables was taken as an integrated assessment of PA. As a result, the average PA score for the city was 3 points, which is a satisfactory level. Then, based on the integral index, the differences in the average assessment of the perceived transport accessibility by administrative districts of the respondents' residence, their gender, age, employment status, and educational level were assessed. The relationship significance was assessed using F-criterionbased one-way ANOVA. 


\section{4-4-Testing Hypothesis 1 (H1): PA for Residential Areas of the City will be Different.}

For residential districts, the relationship between the respondent's residence and PA was identified at a significance level of $6 \%$. Figure 6 presents this relationship.

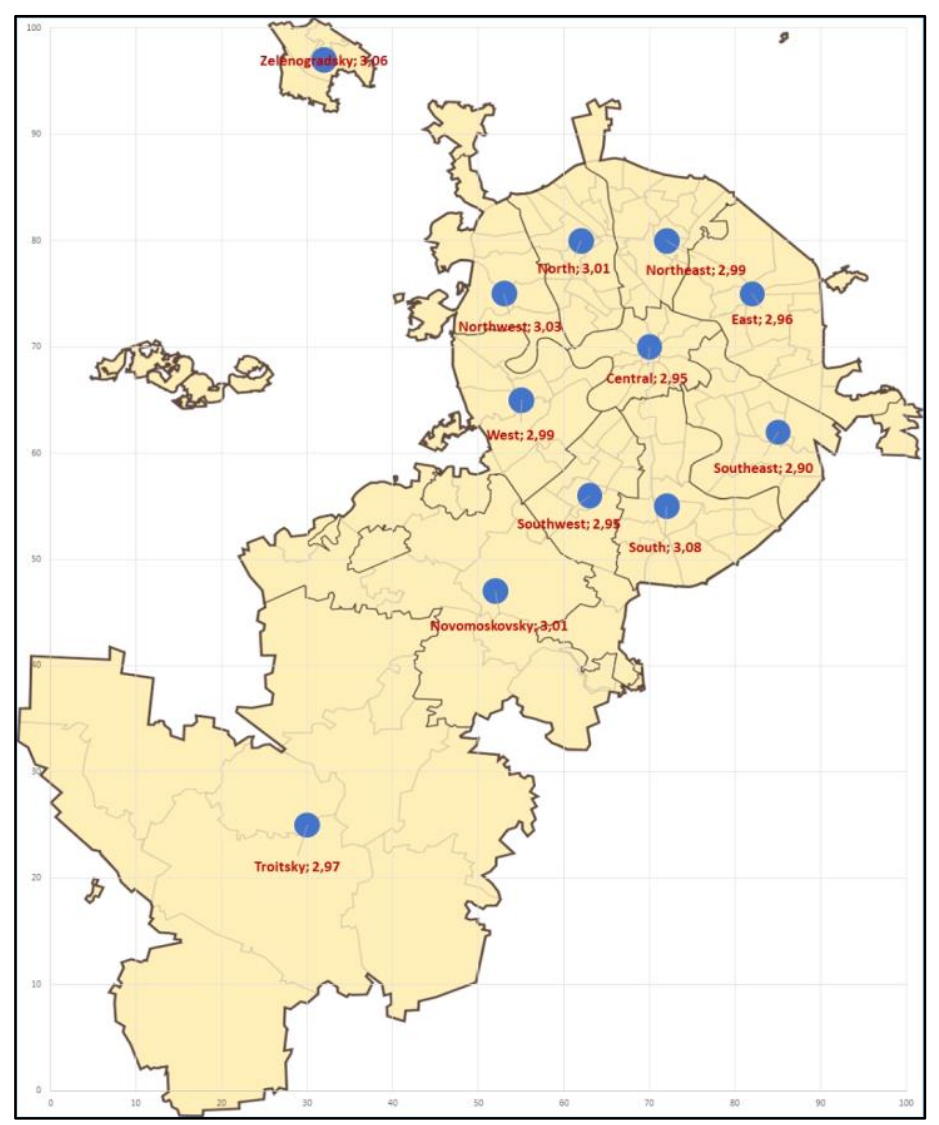

Figure 6. Relationship between the administrative district of Moscow of the respondent's residence and PAAverage PA (on a scale from 1 to 4).

It is easy to see that residents of the South and Zelenogradsky districts are the most satisfied (3.08 and 3.06 scores). The least satisfied are residents of the Southeast district (2.9 points). The difference between the average scores of the South and Southeast districts is $6 \%$. The results show that PA is independent of the distance to the city center and the time to get to the city center. These indicators are often used in assessing OA. For example, if to compare the distance to the center of Moscow from the Zelenogradsky district with the highest PA scores, this distance is $51 \mathrm{~km}$. While from the Southeast district with the lowest PA score, it is $33 \mathrm{~km}$. Table 3 shows Yandex Maps data on the average distance to the city center and the time to get it from the residential areas under study by different transport modes.

Table 3. Assessment of $\mathrm{OA}$ indicators by the time and distance o get from Moscow's districts to the city center $(*$ Red Square is taken as the city center; ** according to [55]).

\begin{tabular}{|c|c|c|c|c|c|c|}
\hline \multirow{2}{*}{$\begin{array}{l}\text { Residential } \\
\text { area }\end{array}$} & \multirow{2}{*}{$\begin{array}{l}\text { Average distance to the city } \\
\text { center, } \mathbf{k m}\end{array}$} & \multicolumn{5}{|c|}{$\begin{array}{l}\text { Time to get to the city center on a weekday (not during rush hours/in rush } \\
\text { hours), min** }\end{array}$} \\
\hline & & By car & By public transport & By walking & By bicycle & By taxi \\
\hline South & 17 & $46 / 70$ & $41 / 43$ & $199 / 199$ & 95 / 97 & $40 / 61$ \\
\hline Zelenogradsky & 45 & $90 / 99$ & $93 / 102$ & $490 / 490$ & $221 / 225$ & $65 / 88$ \\
\hline Northwest & 15 & $31 / 40$ & $41 / 39$ & $171 / 171$ & $98 / 100$ & $25 / 33$ \\
\hline Novomoskovsky & 30 & $62 / 81$ & $72 / 72$ & $314 / 314$ & $143 / 147$ & $50 / 63$ \\
\hline North & 12 & $32 / 29$ & $45 / 45$ & $65 / 65$ & $31 / 33$ & $29 / 29$ \\
\hline Northeast & 16 & $53 / 68$ & $43 / 46$ & $160 / 160$ & $72 / 78$ & $40 / 66$ \\
\hline West & 12 & $32 / 39$ & $52 / 55$ & $136 / 136$ & $62 / 64$ & $28 / 38$ \\
\hline Troitsky & 50 & $95 / 95$ & $128 / 130$ & $525 / 525$ & $242 / 242$ & $81 / 89$ \\
\hline East & 15 & $53 / 45$ & $45 / 45$ & $125 / 125$ & $46 / 62$ & $49 / 43$ \\
\hline Central & 4 & $18 / 35$ & $14 / 18$ & $15 / 15$ & $12 / 17$ & $15 / 19$ \\
\hline Southwest & 27 & $66 / 85$ & $54 / 58$ & $242 / 242$ & $121 / 121$ & $61 / 74$ \\
\hline Southeast & 17 & $68 / 61$ & $47 / 47$ & $159 / 159$ & $82 / 82$ & $54 / 57$ \\
\hline
\end{tabular}


Residents of Zelenogradsky district with high satisfaction with transport accessibility are actually in second place among those who are most distant from the city center, both by distance and by actual travel time. The same is for the Southern administrative district, where the satisfaction was the highest, the actual travel time to distance ratio does not reflect the perception of transport accessibility. At the same time, residents of the Central district with the shortest travel time to the city center assess transport accessibility lower than the city average and districts far from the center.

\section{4-5-Testing Hypothesis 2 (H2): PA for the Same Residential Areas is Different when (if) Residents Prefer Different Travel Modes for Daily Travel}

Figure 7 shows the relationship between the primary travel mode in the city and PA.

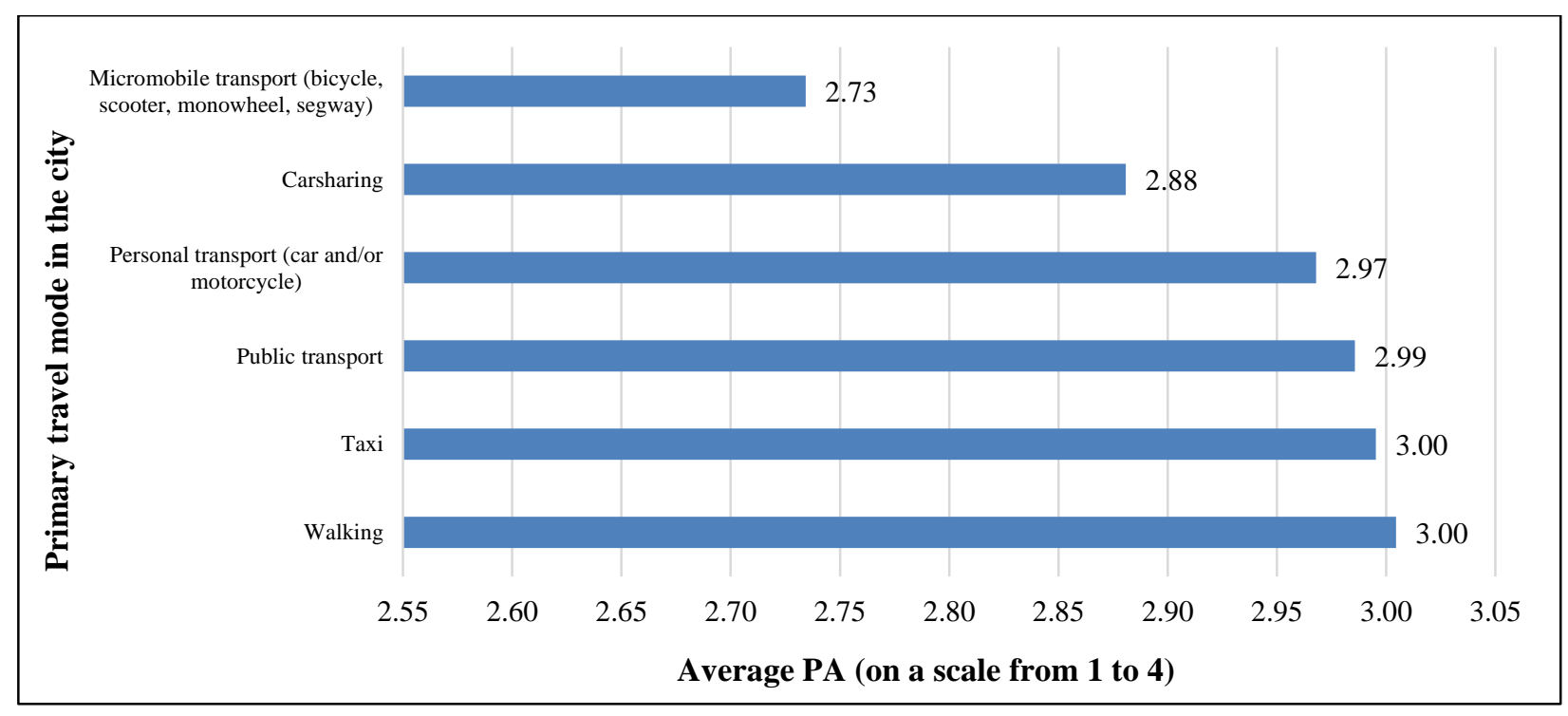

Figure 7. Relationship between the respondent's primary transport mode and PA.

Our study showed that people who walk, use taxes, public and personal transport (car or motorcycle) show the highest values of the PA index (2.97-3.00 scores). Respondents using micro-mobile transport (bicycle, scooter, monowheel, segway) are the least satisfied (2.73 scores). The difference between them is $10 \%$. The carsharing users occupy an intermediate position ( 2.73 scores); the difference with the most satisfied is $4 \%$. Thus, the travel mode in the city is a significant factor affecting the perception of transport accessibility.

\section{4-6- Testing Hypothesis 3 (H3): Social-demographic Factors Define Differences in Perception of Accessibility}

No statistically significant relationship was found between the average PA values by employment status at the $10 \%$ significance level. The relationship between the respondent's gender and educational level and PA was detected at the $5 \%$ significance level. The relationship between the age of the respondent and PA was detected at the 8\% significance level. The average accessibility score for men is slightly lower than for women (2.97 and 3.01, respectively). Figure 8 presents the relationship between the respondent's age and PA.

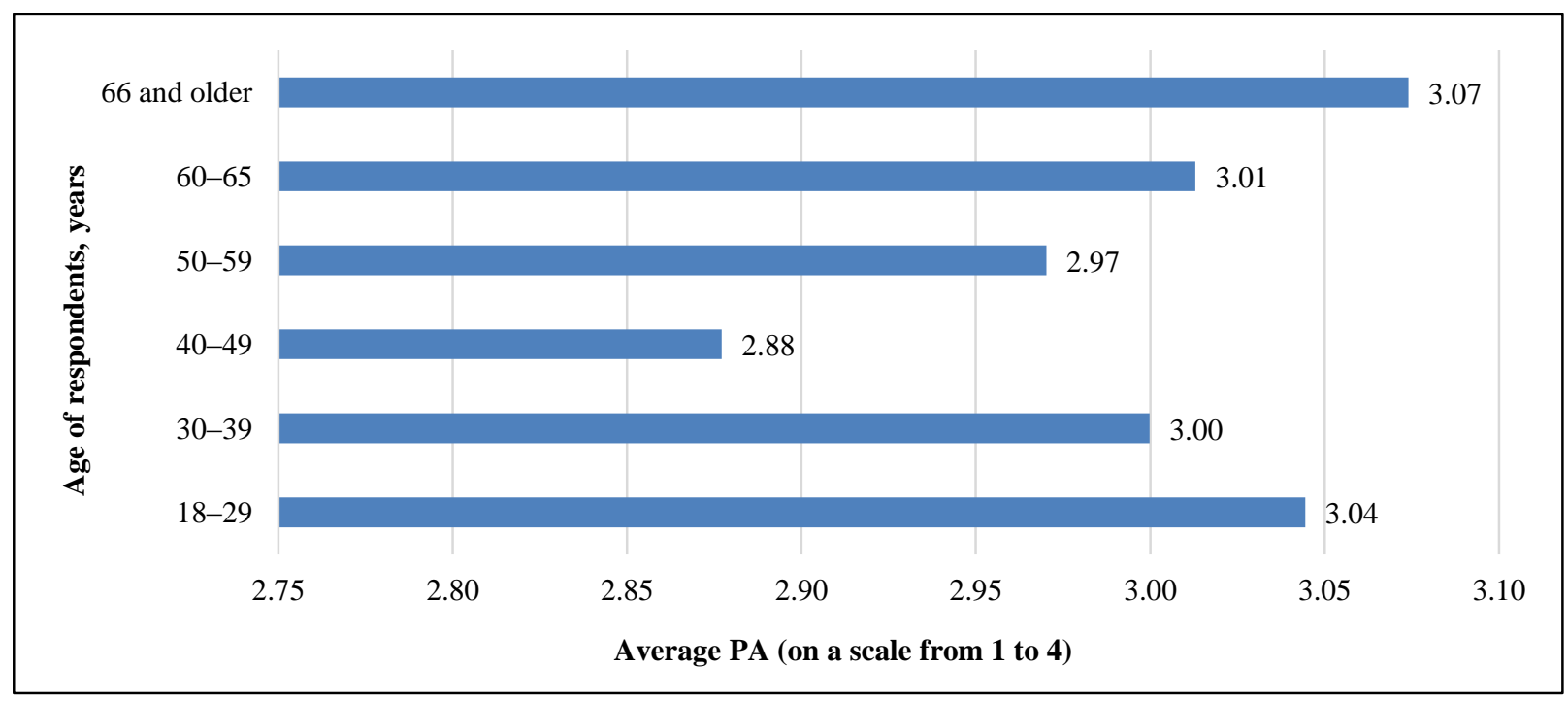

Figure 8. Relationship between respondent's age and PA. 
Elderly and young respondents (66 years and older - 3.07 scores, 18-29 years old -3.04 scores) gave the highest scores of the PA index. The least satisfied are respondents aged 40-49 years (2.88 scores). Figure 9 shows the relationship between the educational level of the respondent and PA.

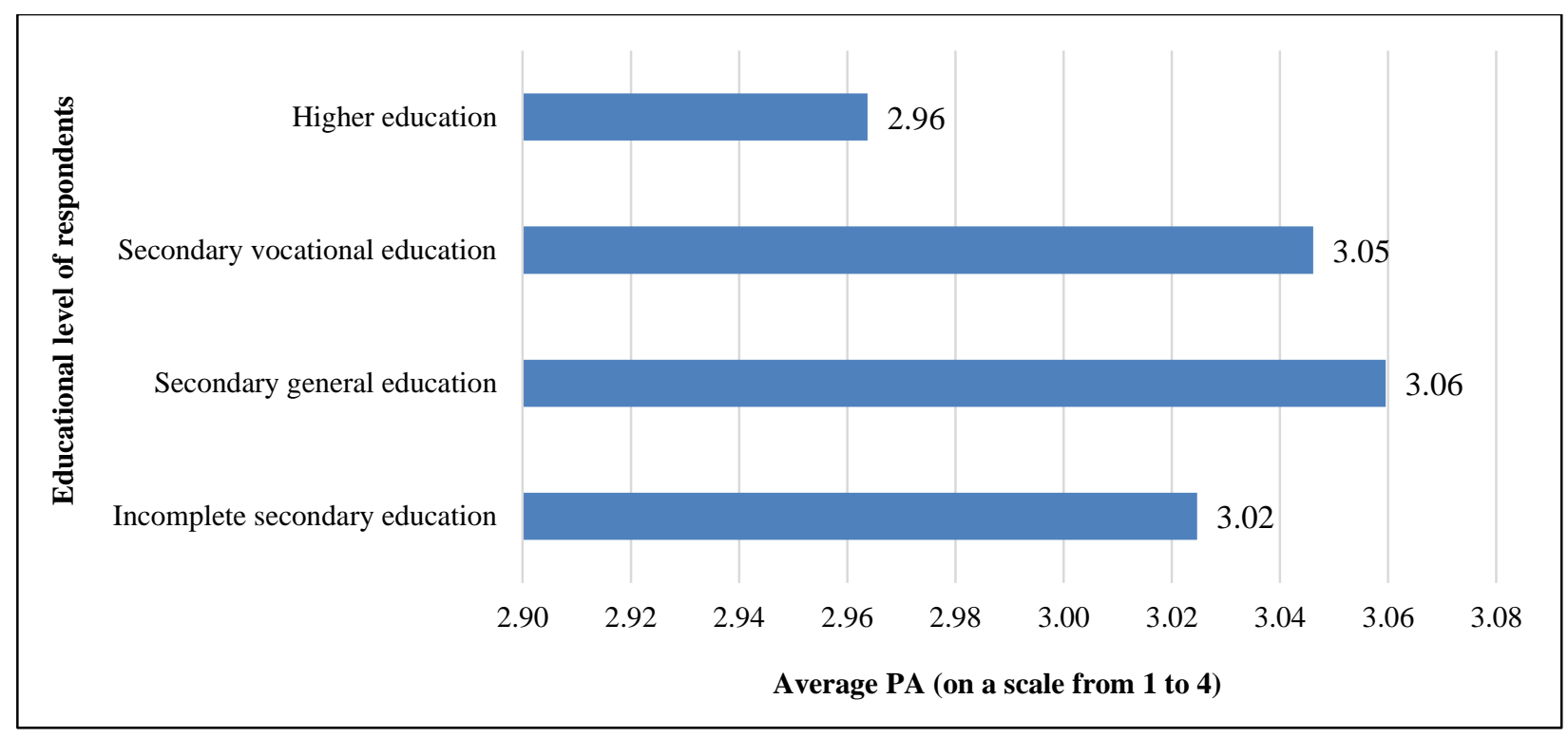

Figure 9. Relationship between respondent's educational level and PA.

Respondents with secondary education gave the highest PA scores (from 3.05 to 3.06), and respondents with higher education - the lowest scores (2.96). The difference between them is $3 \%$.

\section{5- Discussions}

The study analyzed the PA in the city of Moscow, which is the largest city of the Russian Federation and one of the 30 largest urban agglomerations in the world, according to the report of The Department of Economic and Social Affairs of the United Nations [56]. Based on the theoretical framework of PA, we have studied the influence of several factors: a place of residence, socio-demographic characteristics, behavioral factors of individuals (preferences on the way of moving around the city) on the perception of transport accessibility. In order to test the hypotheses, we collected large cross-sectional data from 2,275 respondents living in a metropolitan area. The study results expand knowledge about the possibilities of assessing PA for the largest urban agglomerations in the world. The study provides new insights into the perception of transport accessibility in terms of respondents' socio-demographic characteristics and their transportation habits. The results contribute valuable insights into understanding the impact of residential areas on the assessment of PA in major metropolitan areas. In addition, this study adds to current knowledge about the factors influencing perceptions of accessibility (the study assessed the impact of employment status and educational level on PA).

Hypothesis 1 (PA for Residential Areas of the city will be Different) is confirmed. Ourdatashowthat PA differs in different districts of the city. At the same time, PA does not depend on the residential area remoteness from the city center, so OA indicators cannot explain it. To assess OA as the ease with which an individual can reach any object from the residence [25], we took the city center as such an object. Often travel times and distances to selected destinations serve as indicators. We took indicators of distance and travel time to the city center using different travel modes. The data showed that the perception of accessibility did not depend on OA. Thus, our study supports the conclusion of Pot et al. [43] that the concept of OA does not make it possible to describe the actual situation with the transport accessibility of attraction points for city residents. Based on the study results, we support the authors who propose to use OA as an additional but not the primary indicator to assess the city transport system.

The study findings support Hypothesis 2 (PA for the same Residential areas is Different when (if) Residents Prefer Different Travel Modes for Daily Travel), confirming that the choice of transportation mode in the city affects the assessment of PA. Our results are consistent with those described in the literature, where PA differences depend on how the respondent moves around the city [50].

Our results of differences in PA levels between primary travel modes differ from Lättman's results for Malmö, where the highest PA levels were obtained for "individuals using mainly active sustainable modes (bicycle and walking)" [54]. We got approximately similar high PA scores for travel modes such as walking, cabs, public and personal transport (car or motorcycle).

It should be said that there is the same PA for personal and public transport and taxis since the city of Moscow still has few priority lanes for public transport, which is evident from Table 2 where time on public and personal transport 
is almost the same. The city government is actively restructuring the transport system now, separating lanes for public transport and organizing bicycle lanes. That is critical for improving the city environment, so the government aims to encourage the use of public transport. In this regard, it becomes essential to reduce the travel time when using public transport. It is especially relevant because many studies show that travel and waiting times for public transport significantly impact residents' satisfaction with its accessibility [49].

Hypothesis 3 (Social-Demographic Factors Define Differences in Perception of Accessibility) is partially confirmed. As in [54], statistically significant differences were obtained among respondents of different genders. Similarly, women rated accessibility higher than men. A check of men's and women's transportation preferences showed significant differences only for personal transport preference: $31 \%$ - for men, $24 \%$ - for women. There were no significant differences in preferences for other travel modes. The data obtained show that the travel mode could not significantly affect the perception of transport accessibility of different genders. These differences are the result of some other factors. The check was performed with the help of the construction of contingency tables.

In contrast to [54], our study found statistically significant differences in PA among respondents of different ages. Surprisingly, we found that the highest PA scores were for people over the age of 66 . We can assume that they could compare the accessibility in the years of their youth and now. Interestingly, the lowest score was in the group of respondents aged 40-49. It would be interesting to understand these differences in scores. We checked the differences in transport preferences (in preferred travel modes) in different age groups to assess the effect of travel modes on the perception of accessibility. To verify this, we constructed contingency tables to reveal the impact of respondents' age on their travel modes.

The following results were obtained:

- In age groups from 18 to 49 years, the proportion of respondents who prefer to use public transport ranges from $39 \%$ to $44 \%$, in older groups this proportion rises to 59\% (50-59 years), 66\% (60-65 years) and $85 \%$ (66 years and older);

- A similar picture is in the impact assessment of age on preference for walking: in the age groups of 18 to 49 years, the proportion of respondents who prefer to walk ranges from $21 \%$ to $25 \%$, in older groups, this proportion rises to $35 \%$ (50-59 years), $43 \%$ (60-65 years) and 55\% (66 years and older);

- The less significant impact of age on the preferred use of personal vehicles: from $20 \%$ to $29 \%$ of $18-49$ years old prefer personal vehicles, 50 and over - 33\%-34\%.

From the results, we can assume that older people, who mostly use public transportation and walk, rate the accessibility higher. For the most part, people aged over 66 do not work and do not need to travel long distances around the city. The distances they travel and the frequency of these trips are probably lower than for people aged 4049, which may also affect PA. Our study complements the results of previous studies; in particular, we checked the dependence of PA on employment status, which at the same time did not reveal statistically significant differences in the integral index of PA. We can consider interesting the identified relationship between the educational level and the perception of accessibility for the knowledge development in the field of the impact of socio-demographic characteristics on PA. Remarkably, people with higher education gave the lowest scores on accessibility. It is unlikely that these differences can be explained by preferences in travel modes, as only micro mobile transport and carsharing showed differences in accessibility scores. The contingency tables revealed no significant effect of educational level on preferred transport modes.

\section{6- Conclusions}

According to the study objectives, the analysis of PA in the daily trips of metropolis residents depending on the residence place of the respondent, his/her preferences in the way of moving around the city, socio-demographic characteristics was conducted. The results confirmed that the PA differs in different city residential areas, thus confirming the influence of the respondent's residence on PA. In addition, the results confirmed the difference in the PA depending on the respondent's transportation preferences. There was a significant influence of the individual's transportation preferences on the PA score. The study results showed that several socio-demographic characteristics affect the perception of transport accessibility. Thus, the PA is influenced by gender, age, and educational level. At the same time, employment status showed no statistically significant relationship with the dependent variable (PA).

\section{6-1- Theoretical Implication}

Our study's seven important theoretical implications are as follows: first, it contributes to previous research on the possibility of measuring PA in metropolitan areas and the comparative analysis of OA and RA. Over the past few years, there has been a growing scholarly interest in better understanding perceived transportation accessibility and methods for measuring it. Therefore, the results of this study will add to this developing but as yet understudied field of knowledge. 
Second, this study extended the PA theory by (a) examining the relationship of various factors to the assessment of perceptions of transportation accessibility, (b) by testing the applicability of the PA assessment to the largest metropolitan areas in the world, such as Moscow, which is very important because large metropolitan areas play an increasingly important and "urban grow this closely related to the three dimensions of sustainable development: social, economic, and environmental" [56], and (c) it is confirmed that the use of OA indicators alone does not make it possible to effectively manage the development of a metropolis since the perception of transport accessibility is weakly related to the indicators of OA. Comparison of OA and PA showed that the perception of accessibility does not depend on such indicators reflecting such OA as travel times and distances to selected destinations. Thus, we conclude that OA should not be the primary indicator for assessing the city transport system since it poorly reflects residents' actual attitude and perception of this system. At the same time, "Well-managed urbanization can help to maximize the benefits of high levels of density while minimizing environmental degradation and other potential adverse impacts of the growing number of the city [56].

Third, large cities with ancient history and many architectural monuments, which are the nation's cultural heritage, such as Moscow, have witnessed the rapid development and growth of urban agglomerations and the introduction of various initiatives in the management of megalopolises. For such cities, the opportunities for transport infrastructure development are limited by the location of architectural monuments and cultural heritage monuments. However, evidence-based research on PA assessment, especially in such cities, is currently limited. Previous literature devoted to the study of RA has examined other cultural contexts. Attempts to assess PA in Russia's largest metropolitan areas have not previously been undertaken.

Fourth, the method we used to assess PA allowed us to conduct a comparative analysis with the results of earlier studies and show that the assessment of PA does not depend on the size of the city. Comparing results obtained by Lättman with our results on differences between residential areas, we found a similar result, where OA indicators cannot explain differences in PA. Moreover, in some cases, high OA of residential areas showed a low level of PA (for example, for the Central administrative district) and, opposite, one of the most distant from the center administrative districts with one of the lowest OA (Zelenogradsky) showed one of the highest PA scores.

In the study Lättman et al. [54], suggest that the lack of significant variation in PA is due to the small size of the city of Malmö ("we were expecting bigger differences between the areas, as we know that there are differences in OA"). However, we also did not get significant differences between the PA-scans areas (see Figure 6), although distances in Moscow city are significantly greater than in Malmö. The area of Moscow for 2020 is 2.6 thousand sq. $\mathrm{km}$. [57], which exceeds the area of Malmö 33 times. The present study bridges this gap; therefore, we can conclude that the insignificant differences in PA scores do not depend on the area of the studied territory. Other factors affect this indicator. That is why it is essential to study the relationship between PA with spatially dispersed activities and destinations. We assume that there is a particular comfort zone where daily trips take place. This zone is approximately the same regardless of the residential area; there are no significant differences in the PA index values. Of course, this assumption should be checked with additional research.

Fifth, this study provided insights into using a 4-score scale for the integral index of PA based on the 4-point Likert scale that showed sufficient sensitivity to identify differences in PA. When assessing the methodology for calculating the integral index of PA, we concluded that it is more convenient to use a 4-point Likert scale than the 7-point Likert scale proposed by Katrin Lättman [54], followed by calculating the PA index by calculating the mean from the four items and converting the result to a more familiar scale. Lättman [54] used a 5-point Likert scale for the PA index. Using the 4-point Likert scale avoids the need for subsequent conversion of the PA index to more familiar scales.

Sixth, we checked the influence of two factors (employment status and educational levels) on PA, not found in earlier studies. Employment status did not reveal statistically significant differences in the integral index of PA. Statistically significant differences in PA scores among respondents with different educational levels were obtained. Checking these depending on the preferred way of moving around the city did not show significant differences.

Finally, seventh, our research design can help others interested in understanding the factors that influence PA. In addition, based on the framework we provide, future researchers can focus on the differences in assessments that lie in cognitive processes and require a deeper understanding of the relationships between environment, travel behavior, and individual perceptions that the environment provides.

\section{6-2- Practical Implication}

The three main practical conclusions of our study are as follows. First, the results of our study can be helpful for the city government, as they allow for a deeper understanding of the factors that affect the perception of transport accessibility of the metropolis and both to evaluate the efforts to improve transport accessibility and as targets for management decisions. Second, based on the study results, we propose to use OA as an additional but not the primary indicator to assess the city transport system. That is especially significant because transport accessibility has to improve the quality of life in the metropolis [46, 47], which is not a direct consequence of the number of transport 
modes available to the individual or the ability to reach a large number of places in the city. Many places accessible to an individual are often not suitable or attractive for this individual. Our result of the PA integral index can be used as an indicator or threshold for determining the transport accessibility of the metropolis and its separate territories.

City leaders should also obtain information about influencing factors that can create positive intentions towards using public transport. Our results show that the most significant factor affecting the perception of transport accessibility is the travel mode in the city. The almost identical PA for personal and public transport is an obstacle to the efforts of city authorities to redirect users of personal transport to the use of public transport. There is a need to improve the perception of accessibility using the city's public transport and in this regard, reducing the travel time of public transport becomes crucial. The low level of PA for micro mobile transport (bicycle, scooter, monowheel, segway) is due to the lack of priority lanes, particularly for bicycles. In addition to the lack of bicycle lanes, the limitation of the use of this travel mode is also affected by the limitation associated with the storage of micro-mobility means, long distances in the city, weather conditions, lack of infrastructure, and cultural characteristics that determine transport preferences [58].

Thus, we can conclude that the infrastructure development and its adaptability to a particular travel mode significantly affect the perception of user accessibility. Finally, the study results provide information for management decisions regarding communications with city residents to increase PA. Using the assessment of PA and knowing the factors that influence it, it is possible to use communication policies to change attitudes toward the use of various modes of transportation in the city and form targeted communications to population groups with low PA levels.

\section{6-3- Limitations and future research directions}

A limitation of the study is that it was conducted among residents of one metropolis, so probably that the cultural characteristics of the residents determine selected results. At the same time, our study does not allow us to understand how the accessibility of specific areas such as parks, medical facilities, grocery, and other retail outlets will affect the perception of transport accessibility of individuals, nor assess the impact of individuals' income on PA [29, 37, 38]. We see it advisable to explore this issue in future studies to determine the reasons for any PA assessment and identify factors that might affect the outcome. Another limitation is related to the study design, as the cross-sectional data do not reflect the dynamic nature of the influence of the studied factors. Future researchers may conduct a longitudinal study to understand better the shift of influence of factors on PA to overcome this limitation. We welcome future research to determine the impact of different factors on PA, for example, depending on the location of attraction centers. PA can likely vary depending on where the respondent works, where they are used to having fun, where the sports club, mall, clinic, school, institute, grocery store, and others are. It should also be clarified how the individual navigates the route. It makes sense to assess how the individual perceives the accessibility of other administrative districts of the city, not just the one where the individual lives. Possibly, the perception that the accessibility is higher in the city center leads to an underestimation of the accessibility perception of the individual's place of residence. That is, the factors that affect PA should be studied further.

\section{7- Declarations}

\section{7-1-Author Contributions}

Conceptualization, A.L. and R.S.; methodology, R.S. and I.S.; software, S.M. and A.L.; validation, S.M., R.S. and A.S.; formal analysis, S.M. and A.L.; investigation, R.S. and A.S.; resources, A.L.; data curation, S.M.; writingoriginal draft preparation, R.S., and A.L.; writing - review and editing, R.S. and I.S.; visualization, S.M. and A.L.; supervision, R.S. and I.S.; project administration, S.R.; funding acquisition, I.S. All authors have read and agreed to the published version of the manuscript.

\section{7-2-Data Availability Statement}

The data presented in this study are available on request from the corresponding author.

\section{7-3- Funding}

This research received no external funding.

\section{7-4-Acknowledgments}

The authors would like to acknowledge gratitude to the professors and faculty of the Department of Marketing and the administration of PRUE for the support and technical assistance.

\section{7-5- Conflicts of Interest}

The authors declare that there is no conflict of interests regarding the publication of this manuscript. In addition, the ethical issues, including plagiarism, informed consent, misconduct, data fabrication and/or falsification, double publication and/or submission, and redundancies have been completely observed by the authors. 


\section{8- References}

[1] Grebennikov, V V, D A Munin, A G Levashev, and A.Ju Mihajlov. “Types of Transport Accessibility".'Institution News. Investments. Building Construction. Real Estate 1, no. 2 (2012): 56-60.

[2] Kommersant. "Moskva Stalamirovymliderom Po Zagruzhennostidorog v 2020 Godu”." Kommersant, (January 13, 2021).

[3] Moscow in numbers. Brief Statistical Collection (2021). Available online: https://mosstat.gks.ru/storage/mediabank/18yYprEH/ Москва в цифрах, 2021.pdf (accessed on 20 August 2021).

[4] "Moscow Metro" (2017) Available online: https://gup.mosmetro.ru/o-metropolitene/ (accessed on 20 August 2021).

[5] Sidorchuk, Roman, Dariya Efimova, Irina Lopatinskaya, and Venera Kaderova. "Parametric Approach to the Assessment of Service Quality Attributes of Municipal Passenger Transport in Moscow.” Modern Applied Science 9, no. 4 (2015): $303-11$. doi:10.5539/mas.v9n4p303.

[6] Sidorchuk, Roman, and Irina Skorobogatykh. "Marketing Evaluation of Public Transport Quality Attributes: Review of Two Waves of Research.” Mediterranean Journal of Social Sciences 6, no. 3S3 (2015): 275-82. doi:10.5901/mjss.2015.v6n3s3p275.

[7] Lättman, Katrin, Lars E. Olsson, and Margareta Friman. Development and Test of the Perceived Accessibility Scale (PAC) in Public Transport. Journal of Transport Geography. Vol. 54. International Convention of Psychological Science, 2016. doi:10.1016/j.jtrangeo.2016.06.015.

[8] Directorate-General for Mobility and Transport. "Strategic Plan 2016-2020. Directorate-General for Mobility and Transport" (August 8, 2017).

[9] Bogovic, B. "(Development of Transport System).” Suvremeni Promet, (2017). Available online: http://gov.garant.ru/SESSION/PILOT/main.htm. (accessed on 8 May 2021).

[10] Open budget of Moscow. "Development of Moscow transport system" (2011). Available online: https://budget.mos.ru/budget/gp/passports/01 (accessed on 11 January 2021).

[11] Curl, Angela, John D. Nelson, and Jillian Anable. "Same Question, Different Answer: A Comparison of GIS-Based Journey Time Accessibility with Self-Reported Measures from the National Travel Survey in England." Computers, Environment and Urban Systems 49 (2015): 86-97. doi:10.1016/j.compenvurbsys.2013.10.006.

[12] Thériault, Marius, and François Des Rosiers. "Modelling Perceived Accessibility to Urban Amenities Using Fuzzy Logic, Transportation GIS and Origin-Destination Surveys.” In 7th AGILE Conference on Geographic Information Science, 475-85, 2004.

[13] Lättman, Katrin, Lars E. Olsson, and Margareta Friman. "Development and Test of the Perceived Accessibility Scale (PAC) in Public Transport.” Journal of Transport Geography 54 (2016): 257-63. doi:10.1016/j.jtrangeo.2016.06.015.

[14] Kahle, Lynn R., and Naresh K. Malhotra. "Marketing Research: An Applied Orientation.” Journal of Marketing Research, (1994). doi:10.2307/3151953.

[15] S., Mkhitaryan V, and S A Ajvazyan. "Teoriyaveroyatnostiiprikladnayastatistika.” Tome 1 (2001).

[16] Sidorchuk, Roman, Sergey Vladimirovich Mkhitaryan, Irina Ivanovna Skorobogatykh, Anastasia Alekseevna Stukalova, and Anastasia Vladimirovna Lukina. "Modeling of the Need for Parking Space in the Districts of Moscow Metropolis by Using Multivariate Methods.” Journal of Applied Engineering Science 18, no. 1 (2020): 26-39. doi:10.5937/jaes18-23911.

[17] Hansen, Walter G. "How Accessibility Shapes Land Use.” Journal of the American Planning Association 25, no. 2 (1959): 7376. doi:10.1080/01944365908978307.

[18] Dalvi, M. Q., and K. M. Martin. “The Measurement of Accessibility: Some Preliminary Results.” Transportation 5, no. 1 (1976): 17-42. doi:10.1007/BF00165245.

[19] Geurs, Karst T., and Bert van Wee. "Accessibility Evaluation of Land-Use and Transport Strategies: Review and Research Directions.” Journal of Transport Geography 12, no. 2 (2004): 127-40. doi:10.1016/j.jtrangeo.2003.10.005.

[20] Páez, Antonio, Darren M. Scott, and Catherine Morency. "Measuring Accessibility: Positive and Normative Implementations of Various Accessibility Indicators.” Journal of Transport Geography 25 (2012): 141-53. doi:10.1016/j.jtrangeo.2012.03.016.

[21] Geurs, Karst T., Andrea De Montis, and Aura Reggiani. "Recent Advances and Applications in Accessibility Modelling." Computers, Environment and Urban Systems 49 (2015): 82-85. doi:10.1016/j.compenvurbsys.2014.09.003.

[22] Park, Keunhyun. "Psychological Park Accessibility: A Systematic Literature Review of Perceptual Components Affecting Park Use.” Landscape Research 42, no. 5 (2017): 508-20. doi:10.1080/01426397.2016.1267127.

[23] Ekkel, E. Dinand, and Sjerp de Vries. "Nearby Green Space and Human Health: Evaluating Accessibility Metrics." Landscape and Urban Planning 157 (2017): 214-20. doi:10.1016/j.landurbplan.2016.06.008. 
[24] Guagliardo, Mark F. "Spatial Accessibility of Primary Care: Concepts, Methods and Challenges." International Journal of Health Geographics 3, no. 1 (2004). doi:10.1186/1476-072X-3-3.

[25] Chapman, Susan, and Doug Weir. “Accessibility Planning Methods - NZ Transport Agency Research Report 363,” (2008).

[26] Delafontaine, Matthias, Tijs Neutens, Tim Schwanen, and Nico Van de Weghe. "The Impact of Opening Hours on the Equity of Individual Space-Time Accessibility." Computers, Environment and Urban Systems 35, no. 4 (2011): $276-88$. doi:10.1016/j.compenvurbsys.2011.02.005.

[27] Neutens, Tijs, Matthias Delafontaine, Darren M. Scott, and Philippe De Maeyer. "An Analysis of Day-to-Day Variations in Individual Space-Time Accessibility.” Journal of Transport Geography 23 (2012): 81-91. doi:10.1016/j.jtrangeo.2012.04.001.

[28] Fransen, Koos, Tijs Neutens, Steven Farber, Philippe De Maeyer, Greet Deruyter, and Frank Witlox. "Identifying Public Transport Gaps Using Time-Dependent Accessibility Levels.” Journal of Transport Geography 48 (2015): $176-87$. doi:10.1016/j.jtrangeo.2015.09.008.

[29] Tiznado-Aitken, Ignacio, Juan Carlos Muñoz, and Ricardo Hurtubia. "Public Transport Accessibility Accounting for Level of Service and Competition for Urban Opportunities: An Equity Analysis for Education in Santiago de Chile." Journal of Transport Geography 90 (2021): 102919. doi:10.1016/j.jtrangeo.2020.102919.

[30] Allen, Jeff, and Steven Farber. "A Measure of Competitive Access to Destinations for Comparing Across Multiple Study Regions.” Geographical Analysis 52, no. 1 (2020): 69-86. doi:10.1111/gean.12188.

[31] Saif, Muhammad Atiullah, Mohammad Maghrour Zefreh, and Adam Torok. "Public Transport Accessibility: A Literature Review.” Periodica Polytechnica Transportation Engineering 47, no. 1 (2019): 36-43. doi:10.3311/PPtr.12072.

[32] Shi, Yuji, Simon Blainey, Chao Sun, and Peng Jing. "A Literature Review on Accessibility Using Bibliometric Analysis Techniques.” Journal of Transport Geography 87 (2020): 102810. doi:10.1016/j.jtrangeo.2020.102810.

[33] Márquez, Luis, Juan C. Poveda, and Luis A. Vega. "Factors Affecting Personal Autonomy and Perceived Accessibility of People with Mobility Impairments in an Urban Transportation Choice Context.” Journal of Transport and Health 14 (2019): 100583. doi:10.1016/j.jth.2019.100583.

[34] Guzman, Luis A., Daniel Oviedo, and Carlos Rivera. "Assessing Equity in Transport Accessibility to Work and Study: The Bogotá Region.” Journal of Transport Geography 58 (2017): 236-46. doi:10.1016/j.jtrangeo.2016.12.016.

[35] Guzman, Luis A., and Daniel Oviedo. “Accessibility, Affordability and Equity: Assessing 'pro-Poor' Public Transport Subsidies in Bogotá.” Transport Policy 68 (2018): 37-51. doi:10.1016/j.tranpol.2018.04.012.

[36] Oviedo, Daniel, and Luis A. Guzman. "Revisiting Accessibility in a Context of Sustainable Transport: Capabilities and Inequalities in Bogota.” Sustainability (Switzerland) 12, no. 11 (2020). doi:10.3390/su12114464.

[37] Pot, Felix J., Sierdjan Koster, Taede Tillema, and Peter Jorritsma. "Linking Experienced Barriers during Daily Travel and Transport Poverty in Peripheral Rural Areas: The Case of Zeeland, the Netherlands." European Journal of Transport and Infrastructure Research 20, no. 3 (2020): 29-46. doi:10.18757/ejtir.2020.20.3.4076.

[38] Sun, Yeran, and Piyushimita Thakuriah. "Public Transport Availability Inequalities and Transport Poverty Risk across England.” Environment and Planning B: Urban Analytics and City Science, 2021. doi:10.1177/2399808321991536.

[39] Schiefelbusch, Martin. "Citizen's Involvement and the Representation of Passenger Interests in Public Transport: Dimensions of a Long-Neglected Area of Transport Planning and Policy with Case Studies from Germany." Transport Reviews 25, no. 3 (2005): 261-82. doi:10.1080/0144164042000335904.

[40] Gong, J.W., Y.P. Li, C. Suo, and J. Lv. "Planning Regional Energy System with Consideration of Energy Transition and Cleaner Production under Multiple Uncertainties: A Case Study of Hebei Province, China.” Journal of Cleaner Production 250 (March 2020): 119463. doi:10.1016/j.jclepro.2019.119463.

[41] Burns, Lawrence D., and Thomas F. Golob. "The Role of Accessibility in Basic Transportation Choice Behavior." Transportation 5, no. 2 (1976): 175-98. doi:10.1007/BF00167272.

[42] Axhausen, Kay W., and Tommy Gärling. "Activity-Based Approaches to Travel Analysis: Conceptual Frameworks, Models, and Research Problems: Foreign Summaries.” Transport Reviews 12, no. 4 (1992): 323-41. doi:10.1080/01441649208716826.

[43] Pot, Felix Johan, Bert van Wee, and Taede Tillema. "Perceived Accessibility: What It Is and Why It Differs from Calculated Accessibility Measures Based on Spatial Data." Journal of Transport Geography 94 (2021): 103090. doi:10.1016/j.jtrangeo.2021.103090.

[44] Curl, Angela, John D. Nelson, and Jillian Anable. "Does Accessibility Planning Address What Matters? A Review of Current Practice and Practitioner Perspectives." Research in Transportation Business and Management 2 (2011): 3-11. doi:10.1016/j.rtbm.2011.07.001.

[45] Miller, Eric. "Measuring Accessibility: Methods and Issues" (2020). 
[46] Lotfi, Sedigheh, and M. J. Koohsari. “Analyzing Accessibility Dimension of Urban Quality of Life: Where Urban Designers Face Duality between Subjective and Objective Reading of Place.” Social Indicators Research 94, no. 3 (2009): 417-35. doi:10.1007/s11205-009-9438-5.

[47] Lofti, Sedigheh, and Mohammad Javad Koohsari. "Measuring Objective Accessibility to Neighborhood Facilities in the City (A Case Study: Zone 6 in Tehran, Iran).” Cities 26, no. 3 (2009): 133-40. doi:10.1016/j.cities.2009.02.006.

[48] Lättman, Katrin, Lars E. Olsson, Margareta Friman, and Satoshi Fujii. "Perceived Accessibility, Satisfaction with Daily Travel, and Life Satisfaction among the Elderly." International Journal of Environmental Research and Public Health 16, no. 22 (2019). doi:10.3390/ijerph16224498.

[49] Chaloux, Nick, Geneviève Boisjoly, Emily Grisé, Ahmed El-Geneidy, and David Levinson. "I Only Get Some Satisfaction: Introducing Satisfaction into Measures of Accessibility." Transportation Research Part F: Traffic Psychology and Behaviour 62 (2019): 833-43. doi:10.1016/j.trf.2019.03.008.

[50] Sukhov, Alexandre, Katrin Lättman, Lars E. Olsson, Margareta Friman, and Satoshi Fujii. "Assessing Travel Satisfaction in Public Transport: A Configurational Approach.” Transportation Research Part D: Transport and Environment 93 (2021): 102732. doi:10.1016/j.trd.2021.102732.

[51] Friman, Margareta, Katrin Lättman, and Lars E. Olsson. "Carpoolers’ Perceived Accessibility of Carpooling." Sustainability (Switzerland) 12, no. 21 (2020): 1-13. doi:10.3390/su12218976.

[52] Oña, Juan de, Esperanza Estévez, and Rocío de Oña. "Perception of Public Transport Quality of Service among Regular Private Vehicle Users in Madrid, Spain." Transportation Research Record 2674, no. 2 (2020): 213-24. doi:10.1177/0361198120907095.

[53] Rosstat. "Women and men of Russia. Statistical collection" (2018).

[54] Lättman, Katrin, Lars E. Olsson, and Margareta Friman. "A New Approach to Accessibility - Examining Perceived Accessibility in Contrast to Objectively Measured Accessibility in Daily Travel." Research in Transportation Economics 69 (2018): 501-11. doi:10.1016/j.retrec.2018.06.002.

[55] Yandex Maps (2021). Available online: https://yandex.ru/maps/213/moscow/?ll=37.622504\%2C55.753215\&z=10 (accessed on 10 October 2021).

[56] The Department of Economic and Social Affairs of the United Nations. "World Urbanization Prospects 2018. Highlights" (2019). Available online: https://population.un.org/wup/Publications/Files/WUP2018-Highlights.pdf (accessed on 10 October 2021).

[57] MOSSTAT. "Moskva v cifrah. Kratkijstatisticheskijsbornik”. Russia (2021).

[58] Lukina Anastasiya. "Prospects and Limitations, Illusions and Facts for the Development of Cycling in Moscow." Russian Journal of Management 4, no. 3 (2016): 271-80. doi:10.12737/21954. 